\title{
The impact of high serum bicarbonate levels on mortality in hemodialysis patients
}

\author{
Kyung Yoon Chang ${ }^{1}$, Hyung Wook Kim ${ }^{1}$, Woo Jeong Kim ${ }^{1}$, Yong Kyun Kim², Su-Hyun Kim³, \\ Ho Chul Song ${ }^{2}$, Young Ok Kim ${ }^{4}$, Dong Chan Jin ${ }^{1}$, Euy Jin Choi ${ }^{2}$, Chul Woo Yang ${ }^{5}$, Yong-Lim Kim ${ }^{6}$, \\ Nam-Ho Kim ${ }^{7}$, Shin-Wook Kang ${ }^{8}$, Yon-Su Kim ${ }^{9}$, and Young Soo Kim ${ }^{4}$
}

Department of Internal Medicine, ${ }^{1}$ College of Medicine, St. Vincent's Hospital, The Catholic University of Korea, Suwon; ${ }^{2}$ College of Medicine, Bucheon St. Mary's Hospital, The Catholic University of Korea, Bucheon; ${ }^{3}$ Chung-Ang University College of Medicine, Seoul; ${ }^{4}$ College of Medicine, Uijeongbu St. Mary's Hospital, The Catholic University of Korea, Uijeongbu; ${ }^{5}$ College of Medicine, Seoul St. Mary's Hospital, The Catholic University of Korea, Seoul; ${ }^{6}$ Kyungpook National University School of Medicine, Daegu; ${ }^{7}$ Chonnam National University Medical School, Gwangju;

${ }^{8}$ Yonsei University College of Medicine, Seoul; ' 9 Seoul National University College of Medicine, Seoul, Korea

Received: June 11, 2015

Revised : July 31, 2015

Accepted: August 4, 2015

Correspondence to

Young Soo Kim, M.D.

Division of Nephrology,

Department of Internal Medicine,

College of Medicine, Uijeongbu

St. Mary's Hospital, The Catholic

University of Korea, 271 Cheonbo-ro,

Uijeongbu 11765, Korea

Tel: +82-31-820-3039

Fax: +82-31-847-2719

E-mail: dr52916@catholic.ac.kr
Background/Aims: The optimal serum bicarbonate level is controversial for patients who are undergoing hemodialysis (HD). In this study, we analyzed the impact of serum bicarbonate levels on mortality among HD patients.

Methods: Prevalent HD patients were selected from the Clinical Research Center registry for End Stage Renal Disease cohort in Korea. Patients were categorized into quartiles according to their total carbon dioxide $\left(\mathrm{tCO}_{2}\right)$ levels: quartile 1 , a $\mathrm{tCO}_{2}$ of $<19.4 \mathrm{mEq} / \mathrm{L}$; quartile 2 , a tCO $\mathrm{tC}_{2}$ of 19.4 to $21.5 \mathrm{mEq} / \mathrm{L}$; quartile 3, a tCO $\mathrm{tC}_{2}$ of 21.6 to $23.9 \mathrm{mEq} / \mathrm{L}$; and quartile 4, a $\mathrm{tCO}_{2}$ of $\geq 24 \mathrm{mEq} / \mathrm{L}$. Cox regression analysis was used to calculate the adjusted hazard ratio (HR) and confidence interval (CI) for mortality.

Results: We included 1,159 prevalent HD patients, with a median follow-up period of 37 months. Kaplan-Meier analysis revealed that the all-cause mortality was significantly higher in patients from quartile 4 , compared to those from the other quartiles $(p=0.009$, log-rank test). The multivariate Cox proportional hazard model revealed that patients from quartile 4 had significantly higher risk of mortality than those from quartile 1, 2 and 3, after adjusting for the clinical variables in model 1 (HR, 1.99; 95\% CI, 1.15 to 3.45; $p=0.01$ ) and model 2 (HR, 1.82; 95\% CI, 1.03 to $3.22 ; p=0.04)$.

Conclusions: Our data indicate that high serum bicarbonate levels (a tCO2 of $\geq 24$ $\mathrm{mEq} / \mathrm{L}$ ) were associated with increased mortality among prevalent HD patients. Further effort might be necessary in finding the cause and correcting metabolic alkalosis in the chronic HD patients with high serum bicarbonate levels.

Keywords: Renal dialysis; Bicarbonates; Alkalosis; Mortality

\section{INTRODUCTION}

The current guidelines for managing metabolic acidosis suggest that patients with chronic kidney disease (CKD) and serum bicarbonate concentrations of $<22 \mathrm{mmol} / \mathrm{L}$ should be treated with oral bicarbonate supplementation to maintain their serum bicarbonate concentration within the normal range, unless this treatment is con- 
traindicated [1]. However, there is no clear consensus regarding the level of serum bicarbonate that should be targeted during hemodialysis (HD). Furthermore, the optimal serum bicarbonate level in HD patients has not been fully clarified.

Intradialytic metabolic alkalosis is induced by high dialysate bicarbonate concentrations, volume contraction, or chronic hypoventilation $[2,3]$. High serum bicarbonate levels have also been associated with the correction of metabolic acidosis [3] and improvements in protein turnover and serum branched-chain amino acid levels [4]. However, metabolic alkalosis may also contribute to adverse outcomes. The rapid change in serum bicarbonate levels leads to faster decreases in serum potassium and ionized calcium levels, which can subsequently result in cardiac arrhythmia and prolongation of the corrected QT interval $[5,6]$. This change also results in increased neuromuscular excitability, reduced cerebral blood flow, respiratory suppression, and hemodynamic instability $[7,8]$. Furthermore, it is associated with increased interdialytic weight gain, which could be caused by exposure to higher sodium bicarbonate levels during $\mathrm{HD}$, and these elevated levels subsequently result in intradialytic hypotension [2]. Finally, several studies have reported that serum bicarbonate levels are associated with mortality in end-stage renal disease (ESRD) [3,9-11]. Therefore, in this study, we investigated the impact of stratified serum bicarbonate levels on mortality among HD patients from the Clinical Research Center (CRC) registry for ESRD cohort in Korea.

\section{METHODS}

\section{Study cohort}

All patients in this study participated in the CRC registry for ESRD, which is an ongoing observational prospective cohort study of patients with ESRD at 31 Korean centers. The cohort was started in April 2009, and includes adult ( $>18$ years old) dialysis patients. A total of 1,812 prevalent HD patients were enrolled in this cohort, although 653 patients whose total carbon dioxide $\left(\mathrm{tCO}_{2}\right)$ at enrollment could not be ascertained were excluded from the present analysis. Thus, 1,159 HD patients were included in the present analysis.

Demographic data and clinical data were collected at enrollment, and the assessment of dialysis characteristics and health measurements was performed every 6 months until the end of follow-up. Dates and causes of mortality were immediately reported throughout the follow-up period. The CRC registry for ESRD was approved by the medical ethics committees of all of the participating hospitals, and informed consent was obtained from all patients before their inclusion.

Baseline demographic and clinical data included age, sex, height, weight, body mass index (BMI), causes of ESRD, duration of dialysis, comorbidities, laboratory test results, and therapeutic characteristics. Serum levels of hemoglobin, albumin, blood urea nitrogen (BUN), creatinine, calcium, phosphorus, ferritin, intact parathyroid hormone, and $\mathrm{tCO}_{2}$ were determined using the patients' blood samples. Prevalent HD patients were categorized into quartiles according to their $\mathrm{tCO}_{2}$ levels: quartile 1 , a $\mathrm{tCO}_{2}$ of $<19.4 \mathrm{mEq} / \mathrm{L}$; quartile 2 , a $\mathrm{tCO}_{2}$ of 19.4 to $21.5 \mathrm{mEq} / \mathrm{L}$; quartile 3 , a $\mathrm{tCO}_{2}$ of 21.6 to 23.9 $\mathrm{mEq} / \mathrm{L}$; and quartile 4 , a $\mathrm{tCO}_{2}$ of $\geq 24 \mathrm{mEq} / \mathrm{L}$.

Cardiovascular disease was defined as the presence of coronary heart disease, peripheral vascular disease, and cerebrovascular disease. The normalized protein catabolic rate (nPCR) was calculated using the following urea kinetic modeling formula; PCR $(\mathrm{g} /$ day $)=0.22$ $+(0.036 \times$ intradialytic rise in BUN $\times 24) /($ intradialytic interval); $\mathrm{nPCR}(\mathrm{g} / \mathrm{kg} /$ day $)=$ PCR / standard weight; standard weight $=$ total body water $/ 0.58[12]$.

\section{Outcomes}

The primary clinical outcome of this study was all-cause mortality. All patients were followed until death (event) or the end of the study, with censoring of data at the time the patient underwent renal transplantation, was lost to follow-up, refused to continue participating, or was transferred to a nonparticipating hospital. For each death, the clinical center's principal investigator completed a form that included the cause of death, defined according to the CRC for ESRD study classification.

\section{Statistical analysis}

Data for continuous and normally distributed variables were presented as mean \pm standard deviation $(\mathrm{SD})$, and those for non-normally distributed continuous variables were presented as median and range, as appropriate. Student $t$ test and the Mann-Whitney $U$ test were 
Table 1. Baseline characteristics of the study population according to total $\mathrm{CO}_{2}$

\begin{tabular}{|c|c|c|c|c|c|}
\hline \multirow[b]{2}{*}{ Characteristic } & \multicolumn{4}{|c|}{ Serum $\mathrm{tCO}_{2}, \mathrm{mEq} / \mathrm{L}$} & \multirow[b]{2}{*}{$p$ value } \\
\hline & $\begin{array}{c}\text { Quartile } 1 \\
(\leq 19 \cdot 3, \mathrm{n}=289)\end{array}$ & $\begin{array}{c}\text { Quartile 2 } \\
(19.4-21.5, \mathrm{n}=285)\end{array}$ & $\begin{array}{c}\text { Quartile } 3 \\
(21.6-23.9, \mathrm{n}=284)\end{array}$ & $\begin{array}{c}\text { Quartile } 4 \\
(\geq 24, n=301)\end{array}$ & \\
\hline $\mathrm{tCO}_{2}, \mathrm{mEq} / \mathrm{L}$ & $17.4 \pm 1.5$ & $20.5 \pm 0.6$ & $22.6 \pm 0.6$ & $26.2 \pm 2.2$ & $<0.001$ \\
\hline Age, yr & $57 \pm 13$ & $61 \pm 12$ & $59 \pm 13$ & $59 \pm 13$ & 0.009 \\
\hline Male sex & $147(50.9)$ & $154(54.0)$ & $167(58.8)$ & $197(65.4)$ & 0.002 \\
\hline Duration of dialysis, mon & $5^{1 \pm 52}$ & $46 \pm 51$ & $44 \pm 521$ & $38 \pm 39$ & 0.018 \\
\hline No RRF & $124(71.3)$ & $113(64.9)$ & $134(77.0)$ & $143(72.2)$ & 0.098 \\
\hline Causes of ESRD & & & & & 0.054 \\
\hline Diabetes mellitus & $126(44 \cdot 5)$ & $123(43 \cdot 3)$ & $135(48.0)$ & $161(53.7)$ & \\
\hline Glomerulonephritis & $35(12.4)$ & $44(15 \cdot 5)$ & $29(10.3)$ & $32(10.7)$ & \\
\hline Others/unknown & $122(43.1)$ & $117(41.2)$ & $117(41.6)$ & $107(35 \cdot 6)$ & \\
\hline \multicolumn{6}{|l|}{ Comorbidities } \\
\hline Diabetes mellitus & $118(47 \cdot 4)$ & $116(49.6)$ & $124(52.1)$ & $134(55.1)$ & 0.351 \\
\hline Cardiovascular disease & $53(21.3)$ & $58(24.8)$ & $59(24.8)$ & $75(30.9)$ & 0.105 \\
\hline Systolic blood pressure, mmHg & $145 \pm 20$ & $139 \pm 21$ & $140 \pm 21$ & $140 \pm 20$ & 0.006 \\
\hline Diastolic blood pressure, $\mathrm{mmHg}$ & $77 \pm 13$ & $73 \pm 13$ & $75 \pm 13$ & $76 \pm 12$ & 0.005 \\
\hline Body mass index, kg/m² & $22.7 \pm 3.6$ & $22.4 \pm 3.0$ & $22.3 \pm 3.3$ & $22.0 \pm 3.1$ & 0.067 \\
\hline Hemoglobin, g/dL & $10.8 \pm 1.1$ & $10.6 \pm 1.2$ & $10.5 \pm 1.1$ & $10.5 \pm 1.4$ & 0.003 \\
\hline Serum albumin, g/dL & $3.9 \pm 0.4$ & $3.8 \pm 0.4$ & $3 \cdot 9 \pm 0.4$ & $3.9 \pm 0.5$ & 0.201 \\
\hline Serum creatinine, $\mathrm{mg} / \mathrm{dL}$ & $10.1 \pm 2.8$ & $9.4 \pm 2.6$ & $9.5 \pm 2.7$ & $8.5 \pm 2.9$ & $<0.001$ \\
\hline Serum calcium, mg/dL & $8.6 \pm 0.6$ & $8.8 \pm 0.8$ & $8.9 \pm 0.8$ & $9.1 \pm 0.8$ & $<0.001$ \\
\hline Serum phosphorus, mg/dL & $5 \cdot 5 \pm 1.5$ & $4.8 \pm 1.4$ & $4.9 \pm 1.5$ & $4.4 \pm 1.4$ & $<0.001$ \\
\hline Ferritin & $277 \pm 285$ & $296 \pm 323$ & $306 \pm 320$ & $321 \pm 357$ & 0.443 \\
\hline iPTH, pg/mL & $173.3(74 \cdot 3-18.0)$ & $165.6\left(79.5^{-291.5}\right)$ & $148.0(68.1-279.1)$ & $123.2(56.2-211.2)$ & $<0.001$ \\
\hline nPCR, g/kg/day & $0.94 \pm 0.28$ & $0.90 \pm 0.25$ & $0.91 \pm 0.22$ & $0.86 \pm 0.25$ & 0.039 \\
\hline $\mathrm{spKt} / \mathrm{V}$ & $1.52 \pm 0.32$ & $1.52 \pm 0.31$ & $1.52 \pm 0.35$ & $1.51 \pm 0.32$ & 0.975 \\
\hline Dialysate $\mathrm{HCO}_{3}, \mathrm{mEq} / \mathrm{L}$ & & & & & 0.012 \\
\hline 25 & O & $6(2.7)$ & $1(0.5)$ & $2(1.2)$ & \\
\hline 30 & $142(57 \cdot 3)$ & $127(57.2)$ & $133(65.8)$ & $115(69 \cdot 7)$ & \\
\hline 31 & $20(8.1)$ & $8(3.6)$ & $16(7 \cdot 9)$ & $8(4.8)$ & \\
\hline 32 & $60(24.2)$ & $59(26.6)$ & $39(19 \cdot 3)$ & $29(17.6)$ & \\
\hline 34 & $26(10.5)$ & $22(9.9)$ & $13(6.4)$ & $11(6.7)$ & \\
\hline
\end{tabular}

Values are presented as mean $\pm \mathrm{SD}$, number (\%), or medians (interquartile range). No RRF means 24 hours residual urine volume $<100 \mathrm{~mL}$. The albumin-corrected serum calcium was calculated as: $[4-$ serum albumin $(\mathrm{mg} / \mathrm{dL})] \times 0.8+\mathrm{unadjusted}$ serum calcium $(\mathrm{mg} / \mathrm{dL})$.

$\mathrm{tCO}_{2}$, total carbon dioxide; RRF, residual renal function; ESRD, end-stage renal disease; iPTH, intact parathyroid hormone; nPCR, normalized protein catabolic rate; spKt/V, single pool Kt/V.

used, as appropriate, to evaluated differences in the continuous variables. Categorical variables were presented as percentages, and Pearson chi-square test or Fisher exact test was used to evaluate differences in the cate- gorical variables.

Absolute mortality rates were calculated per 100 person-years of follow-up. The survival curves were estimated using the Kaplan-Meier method and compared 
between quartiles 1, 2, 3, and 4 using the log-rank test. Univariate and multivariate analyses using the Cox proportional hazard regression model were performed to calculate the hazard ratio (HR) with 95\% confidence interval (CI) for all-cause mortality; the reference category was defined as quartile 3 (a tCO $\mathrm{t}_{2}$ of 21.6 to $23.9 \mathrm{mEq} / \mathrm{L}$ ).

For categorical variables, the assumption of proportional hazards over time was assessed by visual inspection of the log-minus-log survival plot. The Cox proportional hazard model was used to calculate the HR with 95\% CI for all-cause mortality. Analyses were adjusted for potential confounders using two models. Model 1 was adjusted for age, sex, BMI, diabetes mellitus, and cardiovascular disease, while model 2 was adjusted for model 1 plus serum hemoglobin levels, serum albumin levels, and serum phosphorus levels and nPCR.

All statistical analyses were performed using SPSS version 19.0 (IBM Co., Armonk, NY, USA), and a $p<0.05$ was considered statistically significant.

\section{RESULTS}

\section{Patient characteristics}

A total of 1,159 prevalent HD patients were included in the present analysis. The mean patient age was $59 \pm 13$ years and the mean $\mathrm{tCO}_{2}$ was $21.7 \pm 3.5 \mathrm{mEq} / \mathrm{L}$. The main causes of ESRD were diabetes mellitus (48\%), glomerulonephritis (12\%), and other or unknown causes (40\%). The baseline characteristics of the study population according to $\mathrm{tCO}_{2}$ are shown in Table 1. Quartile 1 contained 289 patients $(24.9 \%)$, quartile 2 contained 285 patients $(24.6 \%)$, quartile 3 contained 284 patients $(24.5 \%)$, and quartile 4 contained 301 patients (26\%). The mean
$\mathrm{tCO}_{2}$ was $17.4 \pm 1.5 \mathrm{mEq} / \mathrm{L}$ for patients in quartile 1, $20.5 \pm$ $0.6 \mathrm{mEq} / \mathrm{L}$ for patients in quartile 2, $22.6 \pm 0.6 \mathrm{mEq} / \mathrm{L}$ for patients in quartile 3 , and $26.2 \pm 2.2 \mathrm{mEq} / \mathrm{L}$ for patients in quartile 4. Compared to the patients in other quartiles, the patients in quartile 4 were more likely to be male, have a shorter duration of dialysis, and have lower levels of serum hemoglobin, phosphorus, and intact parathyroid hormone. However, there was no difference in the prevalence of comorbidities, BMI, serum albumin, ferritin, single pool Kt/V, and dialysate bicarbonate concentrations when the quartiles were compared.

\section{All-cause mortality according total $\mathrm{CO}_{2}$}

The median follow-up period was 37 months (interquartile range, 24 to 55), and 266 patients were censored the study during the follow-up period. The reasons for censoring included transfer to a nonparticipating hospital ( $\mathrm{n}=102)$, kidney transplantation $(\mathrm{n}=80)$, refusal to continue participating $(n=32)$, and other reasons $(n=52)$.

There were 112 deaths during the follow-up period, and the leading causes of deaths were cardiovascular diseases (44.6\% of all deaths) and infectious diseases (16.1\% of all deaths). Table 2 shows the causes of deaths in each group, all-cause mortality and cardiovascular mortality were significantly higher in quartile $4(p=0.021)$.

The absolute mortality rate during the median followup period of 37 months was 3.17 deaths per 100 personyears. Fig. 1 shows the Kaplan-Meier survival curve for mortality according to $\mathrm{tCO}_{2}$, and mortality was observed to be significantly higher in patients from quartile 4 compared to those from the other quartiles $(p=0.009$, log-rank test).

In the univariate Cox regression analysis, all-cause mortality was significantly associated with old age $(>65$

Table 2. Causes of deaths in each group

\begin{tabular}{|c|c|c|c|c|c|}
\hline \multirow[b]{2}{*}{ Diseases } & \multicolumn{4}{|c|}{ Serum $\mathrm{tCO}_{2}, \mathrm{mEq} / \mathrm{L}$} & \multirow[b]{2}{*}{$p$ value } \\
\hline & $\begin{array}{c}\text { Quartile } 1 \\
(\leq 19 \cdot 3, \mathrm{n}=289)\end{array}$ & $\begin{array}{c}\text { Quartile 2 } \\
(19.4-21.5, \mathrm{n}=285)\end{array}$ & $\begin{array}{c}\text { Quartile } 3 \\
(21.6-23.9, \mathrm{n}=284)\end{array}$ & $\begin{array}{c}\text { Quartile } 4 \\
(\geq 24, \mathrm{n}=301)\end{array}$ & \\
\hline Cardiovascular diseases & $8(38.1)$ & $12(48.0)$ & $8(33.3)$ & $22(52.4)$ & 0.021 \\
\hline Infectious diseases & $5(23.8)$ & $2(8.0)$ & $5(20.8)$ & $6(14 \cdot 3)$ & 0.599 \\
\hline Others & $8(38.1)$ & $11(44 \cdot 0)$ & $11(45 \cdot 8)$ & $14(33 \cdot 3)$ & 0.695 \\
\hline Total & $21(18.8)$ & $25(22.3)$ & $24(21.4)$ & $42(37 \cdot 5)$ & 0.029 \\
\hline
\end{tabular}

Values are presented as number (\% of deaths).

$\mathrm{tCO}_{2}$, total carbon dioxide. 


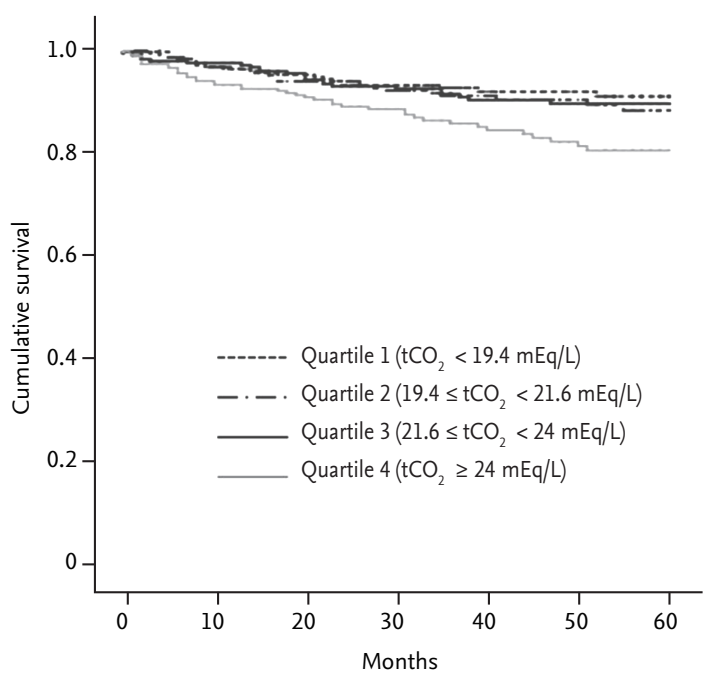

Patients at risk, $n$

$\begin{array}{llllllll}\text { Quartile 1 } & 289 & 256 & 238 & 224 & 216 & 211 & 208 \\ \text { Quartile 2 } & 285 & 257 & 232 & 217 & 213 & 205 & 203 \\ \text { Quartile 3 } & 284 & 258 & 234 & 217 & 204 & 198 & 198 \\ \text { Quartile 4 } & 301 & 249 & 217 & 196 & 183 & 173 & 171\end{array}$

Figure 1. Kaplan-Meier survival curve for mortality according to total carbon dioxide $\left(\mathrm{tCO}_{2}\right)$ in prevalent hemodialysis patients $(p=0.009$, log-rank). years), male sex, diabetes mellitus, cardiovascular disease, BMI, serum hemoglobin, serum albumin, serum creatinine, serum phosphorus, and nPCR. Relative to quartile 3, the HR for all-cause mortality in quartile 4 was 1.85 (95\% CI, 1.12 to 3.05; $p=0.02$ ). All-cause mortality was positively correlated with old age, diabetes mellitus, and cardiovascular disease, and was negatively correlated with serum levels of hemoglobin, albumin, creatinine, and phosphorus (Table 3).

To evaluate $\mathrm{tCO}_{2}$ as an independent predictor for allcause mortality, multivariate Cox regression analysis was performed (Table 4). All-cause mortality was not significantly different when we compared quartile 1, 2, and 3 (the reference category), after adjusting for age, sex, BMI, diabetes mellitus, and cardiovascular disease (model 1) or for age, BMI, diabetes mellitus, cardiovascular disease, serum levels of albumin, hemoglobin, phosphorus and nPCR (model 2). However, quartile 4 had a significantly higher risk of all-cause mortality, compared to quartile 1, 2, and 3 in model 1 (HR, 1.99; 95\% CI, 1.15 to $3.45 ; p=0.01$ ) and model $2(\mathrm{HR}, 1.82 ; 95 \%$ CI, 1.03 to $3.22 ; p=0.04$ ).

Table 3. Univariate Cox regression analysis of mortality

\begin{tabular}{|c|c|c|c|}
\hline Variable & $\mathrm{HR}$ & $95 \% \mathrm{CI}$ & $p$ value \\
\hline Quartile $1\left(\mathrm{tCO}_{2}<19.4\right)$ & 0.86 & $0.48-1.55$ & 0.62 \\
\hline Quartile $2\left(19.4 \leq \mathrm{tCO}_{2}<21.6\right)$ & 1.05 & $0.60-1.84$ & 0.86 \\
\hline Quartile $3\left(21.6 \leq \mathrm{tCO}_{2}<24\right)$ & & Reference & \\
\hline Quartile $4\left(\mathrm{tCO}_{2} \geq 24\right)$ & 1.85 & $1.12-3.05$ & 0.02 \\
\hline Age, yr & 1.06 & $1.04-1.08$ & $<0.01$ \\
\hline Male (vs. female) & 1.44 & $0.98-2.13$ & 0.07 \\
\hline Duration of dialysis, mon & 1.00 & $0.99-1.00$ & 0.97 \\
\hline Diabetes mellitus (vs. none) & 1.82 & $1.20-2.78$ & $<0.01$ \\
\hline Cardiovascular disease (vs. none) & 2.15 & $1.43-3.22$ & $<0.01$ \\
\hline Body mass index, kg/m² & 0.93 & $0.88-0.99$ & 0.03 \\
\hline Hemoglobin, g/dL & 0.80 & $0.69-0.94$ & $<0.01$ \\
\hline Serum albumin, g/dL & 0.31 & $0.21-0.45$ & $<0.01$ \\
\hline Serum creatinine, g/dL & 0.84 & $0.78-0.90$ & $<0.01$ \\
\hline Serum phosphorus, mg/dL & 0.84 & $0.73-0.96$ & $<0.01$ \\
\hline Dialysate $\mathrm{HCO}_{3}, \mathrm{mEq} / \mathrm{L}$ & 0.92 & $0.79-1.08$ & 0.29 \\
\hline nPCR, g/kg/day & 0.35 & $0.13-0.95$ & 0.039 \\
\hline
\end{tabular}

$\mathrm{HR}$, hazard ratio; CI, confidence interval; $\mathrm{tCO}_{2}$, total carbon dioxide; $\mathrm{nPCR}$, normalized protein catabolic rate. 
Table 4. Multivariate Cox regression analysis of mortality

\begin{tabular}{|c|c|c|c|c|c|c|}
\hline \multirow{2}{*}{ Variable } & \multicolumn{3}{|c|}{ Model $1^{\mathrm{a}}$} & \multicolumn{3}{|c|}{ Model $2^{b}$} \\
\hline & HR & $95 \% \mathrm{CI}$ & $p$ value & $\mathrm{HR}$ & $95 \% \mathrm{CI}$ & $p$ value \\
\hline \multicolumn{7}{|c|}{$\mathrm{tCO}_{2}, \mathrm{mEq} / \mathrm{L}$} \\
\hline$<19.4$ & 1.16 & $0.61-2.21$ & 0.65 & 1.27 & $0.66-2.44$ & 0.47 \\
\hline $19.4-21.5$ & 1.09 & $0.59-2.02$ & 0.78 & 1.11 & $0.60-2.07$ & 0.74 \\
\hline $21.6-23.9$ & \multicolumn{3}{|c|}{1 (reference) } & \multicolumn{3}{|c|}{1 (reference) } \\
\hline$\geq 24$ & 1.99 & $1.15-3.45$ & 0.01 & 1.82 & $1.03-3.22$ & 0.04 \\
\hline \multicolumn{7}{|c|}{$\mathrm{tCO}_{2}, \mathrm{mEq} / \mathrm{L}$} \\
\hline$<19.4$ & \multicolumn{3}{|c|}{1 (reference) } & \multicolumn{3}{|c|}{1 (reference) } \\
\hline $19.4-21.5$ & 0.94 & $0.50-1.77$ & 0.85 & 0.88 & $0.46-1.67$ & 0.68 \\
\hline $21.6-23.9$ & 0.86 & $0.45^{-1.64}$ & 0.65 & 0.79 & $0.41-1.51$ & 0.47 \\
\hline$\geq 24$ & 1.71 & $0.97-3.03$ & 0.06 & 1.43 & $0.77-2.66$ & 0.25 \\
\hline \multicolumn{7}{|c|}{$\mathrm{tCO}_{2}, \mathrm{mEq} / \mathrm{L}$} \\
\hline$<19.4$ & 1.06 & $0.56-2.01$ & 0.85 & 1.14 & $0.60-2.18$ & 0.68 \\
\hline $19.4-21.5$ & \multicolumn{3}{|c|}{1 (reference) } & \multicolumn{3}{|c|}{1 (reference) } \\
\hline $21.6-23.9$ & 0.92 & $0.50-1.69$ & 0.78 & 0.90 & $0.48-1.67$ & 0.74 \\
\hline$\geq 24$ & 1.82 & $1.06-3.13$ & 0.03 & 1.64 & $0.92-2.93$ & 0.10 \\
\hline \multicolumn{7}{|c|}{$\mathrm{tCO}_{2}, \mathrm{mEq} / \mathrm{L}$} \\
\hline$<19.4$ & 0.58 & $0.33-1.03$ & 0.06 & 0.70 & $0.38-1.29$ & 0.25 \\
\hline $19.4-21.5$ & 0.55 & $0.32-0.94$ & 0.03 & 0.61 & $0.34^{-1.09}$ & 0.10 \\
\hline $21.6-23.9$ & 0.50 & $0.29-0.87$ & 0.01 & 0.55 & $0.31-0.97$ & 0.04 \\
\hline$\geq 24$ & \multicolumn{3}{|c|}{1 (reference) } & \multicolumn{3}{|c|}{1 (reference) } \\
\hline
\end{tabular}

$\mathrm{tCO}_{2}$, total carbon dioxide; HR, hazard ratio; CI, confidence interval.

${ }^{a}$ Model 1: multivariate model including age, sex, body mass index, diabetes mellitus, and cardiovascular disease.

${ }^{b}$ Model 2: multivariate model including model $1+$ albumin, hemoglobin, phosphorus level, and normalized protein catabolic rate.

\section{DISCUSSION}

As serum bicarbonate levels continuously decrease during the interdialytic interval, HD patients may experience intermittent metabolic acidosis and intradialytic alkalosis. In this prospective observational study of the impact of high serum bicarbonate levels on mortality among $\mathrm{HD}$ patients, we found that the group with a $\mathrm{tCO}_{2}$ of $\geq 24 \mathrm{mEq} / \mathrm{L}$ had a significantly higher risk of mortality compared with the reference group.

The association between serum bicarbonate levels and mortality remains controversial. Bommer et al. [9] have reported that a U-curve best represented the association between predialysis serum bicarbonate levels and the risk of mortality or hospitalization and in their study, both high (> $24 \mathrm{mEq} / \mathrm{L})$ and low (<19 mEq/L) serum bi- carbonate levels were associated with an increased risk of mortality and hospitalization. In addition, other studies reported that a low serum bicarbonate in dialysis patients is a surrogate of better nutritional status with greater survival $[3,10]$. Unlike previous reports, we observed increased mortality in the group with a $\mathrm{tCO}_{2}$ of $\geq 24 \mathrm{mEq} / \mathrm{L}$ independent from nPCR, a nutritional marker. Healthy diets usually include high protein intake, which increases acid load and contributes to predialysis metabolic acidosis. High protein intake is also accompanied by high phosphorus intake, as suggested by the discovery of an inverse correlation between serum bicarbonate and serum phosphorus levels. Uribarri et al. [4] have reported that $\mathrm{tCO}_{2}$ was negatively correlated with the nPCR, which suggests that patients with higher $\mathrm{tCO}_{2}$ levels have lower protein intake. In our study, 
nPCR was related to the mortality of the chronic HD patients in univariate analysis $(p=0.04)$; however, was not related to the mortality in the multivariate analysis $(p=$ 0.361). Our data showed that the $\mathrm{tCO}_{2}$ of $\geq 24 \mathrm{mEq} / \mathrm{L} \mathrm{lev-}$ el was associated with the increased mortality independent from the nPCR level in the chronic HD patients. Therefore, increased mortality in the group with a $\mathrm{tCO}_{2}$ of $\geq 24 \mathrm{mEq} / \mathrm{L}$ level might be associated with metabolic alkalosis itself.

In some reports, high dialysate bicarbonate concentrations may contribute to adverse outcomes through the development of postdialysis metabolic alkalosis and the higher dialysate to serum bicarbonate gradients results in higher bicarbonate transfer during dialysis $[2,13,14]$. In the Dialysis Outcomes and Practice Patterns Study (DOPPS), the average dialysate bicarbonate concentration was $35.5 \pm 2.3 \mathrm{mEq} / \mathrm{L}$ [2]. However, in our study, the dialysate bicarbonate concentrations did not affect the association between high serum bicarbonate levels and increased mortality. Due to the lack of high dialysate bicarbonate concentrations in Korea, the dialysate bicarbonate concentrations are relatively low (30.9 \pm $1.6 \mathrm{mEq} / \mathrm{L})$.

In our study, all-cause mortality and cardiovascular mortality were significantly higher in the $\mathrm{tCO}_{2}$ of $\geq 24$ $\mathrm{mEq} / \mathrm{L}$ group. In this context, intradialytic metabolic alkalosis might result in hemodynamic instability, because of the decreased levels of serum potassium and ionized calcium, as well as muscle cramps and respiratory suppression $[5,6]$.

In addition, our results indicate that serum $\mathrm{tCO}_{2}$ levels were negatively correlated with hemoglobin and phosphorus levels. It is well known that albumin and BMI are associated strongly and inversely associated with mortality and hospitalization [15-17]. Furthermore, related comorbidities may alter the acid load and affect the association between mortality and acidosis in dialysis patients, as these comorbidities frequently reduce appetite, leading to decreased protein intake and eventually to a reduced serum albumin level, which is a strong predictor for increased risk of mortality.

Our study has several potential limitations. First, there was lack of data on the exact timing of the blood sampling for predialysis $\mathrm{tCO}_{2}$ (at the beginning of the week or midweek). Predialysis serum bicarbonate levels are known to be significantly higher on Wednesdays and Fridays, compared to those obtained on Mondays. The timing of blood sampling affects the predialysis $\mathrm{tCO}_{2}$ levels, which may have influenced our findings. For example, Bommer et al. [9] collected midweek $\mathrm{tCO}_{2}$ data, and their patients with midweek $\mathrm{tCO}_{2}$ levels of 20.1 to $21.0 \mathrm{mEq} / \mathrm{L}$ would commonly leave the dialysis units with normal acid-base balance or a mild metabolic alkalosis. Second, our study did not fully consider the patients' nutritional status, such as calorie intake and dietary protein intake. Third, we did not consider physical activity, such as respiratory function, and we did not exclude patients with chronic lung disease. Forth, we did not consider medications that might affect the acidbase balance, such as Sevelamer hydrochloride, which is a non-calcium based phosphate binder. Each Sevelamer molecule includes an amount of nitrogen and chloride, which may lead to a decrease in the bicarbonate levels and an increase in the calculated normalized protein nitrogen appearance $[10,18]$. These results indicate an inverse association between serum bicarbonate and serum phosphorus. Fifth, despite the multicenter design of this study, the cohort consisted exclusively of Korean patients. Thus, it is unclear whether our results can be generalized to other ethnic groups.

In conclusion, high serum bicarbonate levels $\left({\mathrm{a} \mathrm{tCO}_{2}}\right.$ of $\geq 24 \mathrm{mEq} / \mathrm{L}$ ) were associated with increased mortality among prevalent HD patients. Our results suggest that further research might be necessary to find the cause of metabolic alkalosis in order to correct metabolic alkalosis, especially, in the chronic HD patients with high serum bicarbonate levels.

\section{KEY MESSAGE}

1. High serum bicarbonate levels (a total carbon dioxide of $\geq 24 \mathrm{mEq} / \mathrm{L}$ ) were associated with increased mortality among prevalent hemodialysis (HD) patients.

2. Further effort might be necessary in finding the cause and correcting metabolic alkalosis in the chronic HD patients with high serum bicarbonate levels.

\section{Conflict of interest}

No potential conflict of interest relevant to this article 
was reported.

\section{Acknowledgments}

This work was supported by a grant from the Korea Healthcare Technology R\&D Project, Ministry of Health and Welfare, Republic of Korea (HI10C2O2O).

\section{REFERENCES}

1. Levin A, Stevens PE. Summary of KDIGO 2012 CKD guideline: behind the scenes, need for guidance, and a framework for moving forward. Kidney Int 2014;85:49-61.

2. Tentori F, Karaboyas A, Robinson BM, et al. Association of dialysate bicarbonate concentration with mortality in the Dialysis Outcomes and Practice Patterns Study (DOPPS). Am J Kidney Dis 2013;62:738-746.

3. Chen W, Abramowitz MK. Treatment of metabolic acidosis in patients with CKD. Am J Kidney Dis 2014;63:311-317.

4. Uribarri J, Levin NW, Delmez J, et al. Association of acidosis and nutritional parameters in hemodialysis patients. Am J Kidney Dis 1999;34:493-499.

5. Heguilen RM, Sciurano C, Bellusci AD, et al. The faster potassium-lowering effect of high dialysate bicarbonate concentrations in chronic haemodialysis patients. Nephrol Dial Transplant 2005;20:591-597.

6. Di Iorio B, Torraca S, Piscopo C, et al. Dialysate bath and QTc interval in patients on chronic maintenance hemodialysis: pilot study of single dialysis effects. J Nephrol 2012;25:653-667.

7. Sethi D, Curtis JR, Topham DL, Gower PE. Acute metabolic alkalosis during haemodialysis. Nephron 1989;51:119120.

8. Kaye M, Somerville PJ, Lowe G, Ketis M, Schneider W. Hypocalcemic tetany and metabolic alkalosis in a dialysis patient: an unusual event. Am J Kidney Dis 1997;30:440444 .

9. Bommer J, Locatelli F, Satayathum S, et al. Association of predialysis serum bicarbonate levels with risk of mortality and hospitalization in the Dialysis Outcomes and Practice Patterns Study (DOPPS). Am J Kidney Dis 2004;44:661-671.

10. Wu DY, Shinaberger CS, Regidor DL, McAllister CJ, Kopple JD, Kalantar-Zadeh K. Association between serum bicarbonate and death in hemodialysis patients: is it better to be acidotic or alkalotic? Clin J Am Soc Nephrol 2006;1:70-78.

11. Vashistha T, Kalantar-Zadeh K, Molnar MZ, Torlen K, Mehrotra R. Dialysis modality and correction of uremic metabolic acidosis: relationship with all-cause and cause-specific mortality. Clin J Am Soc Nephrol 2013;8:254-264.

12. Depner TA, Daugirdas JT. Equations for normalized protein catabolic rate based on two-point modeling of hemodialysis urea kinetics. J Am Soc Nephrol 1996;7:780785 .

13. Gabutti L, Ferrari N, Giudici G, Mombelli G, Marone C. Unexpected haemodynamic instability associated with standard bicarbonate haemodialysis. Nephrol Dial Transplant 2003;18:2369-2376.

14. Graham KA, Hoenich NA, Goodship TH. Pre and interdialytic acid-base balance in hemodialysis patients. Int $\mathrm{J}$ Artif Organs 2001;24:192-196.

15. Pifer TB, McCullough KP, Port FK, et al. Mortality risk in hemodialysis patients and changes in nutritional indicators: DOPPS. Kidney Int 2002;62:2238-2245.

16. Mapes DL, Lopes AA, Satayathum S, et al. Health-related quality of life as a predictor of mortality and hospitalization: the Dialysis Outcomes and Practice Patterns Study (DOPPS). Kidney Int 2003;64:339-349.

17. Leavey SF, Strawderman RL, Young EW, et al. Cross-sectional and longitudinal predictors of serum albumin in hemodialysis patients. Kidney Int 2000;58:2119-2128.

18. Thet Z, Win AK, Pedagogos E, Beavis J, Crikis S, Nelson C. Differential effects of phosphate binders on pre-dialysis serum bicarbonate in end-stage kidney disease patients on maintenance haemodialysis. BMC Nephrol 2013;14:205. 